\title{
IMR
}

\section{Performance of peanut mutants and their offspring generated from mixed high-energy particle field radiation and tissue culture}

\author{
J.S. Wang ${ }^{1}$, L.X. Qiao ${ }^{1}$, L.S. Zhao ${ }^{2}$, P. Wang ${ }^{1}$, B.T. Guo ${ }^{1}$, L.X. Liu $^{2}$ and \\ J.M. Sui ${ }^{1}$ \\ ${ }^{1}$ Key Laboratory of Plant Biotechnology in Universities of Shandong, \\ Key Laboratory of Qingdao Major Crop Germplasm Resource Innovation \\ and Application, College of Life Science, Qingdao Agricultural University, \\ Qingdao, China \\ ${ }^{2}$ National Key Facility for Crop Gene Resources and Genetic Improvement, \\ Institute of Crop Science, China Academy of Agricultural Sciences, \\ National Center of Space Mutagenesis for Crop Improvement, Beijing, China \\ Corresponding author: J.M. Sui / L.X. Liu \\ E-mail: suijiongming@163.com / liuluxiang@caas.cn
}

Genet. Mol. Res. 14 (3): 10837-10848 (2015)

Received March 4, 2015

Accepted June 18, 2015

Published September 9, 2015

DOI http://dx.doi.org/10.4238/2015.September.9.22

\begin{abstract}
To develop new ways to breed peanut, we irradiated seeds of the Luhua 11 cultivar with a mixed high-energy particle field at different doses. The embryonic leaflets were extracted as explants and incubated on somatic embryo induction medium and then on somatic embryo germination and regeneration medium. After being grafted, the $\mathrm{M}_{1}$-generation plants were transplanted, and seeds from each $\mathrm{M}_{1}$-generation plant were harvested. In the following year, the $\mathrm{M}_{2}$ generation seeds were planted separately. Some $\mathrm{M}_{2}$-generation plants showed distinct character segregation relative to the mutagenic parent in terms of vigor, fertility, plant height, branch number, and pod size and shape. $\mathrm{M}_{2}$-generation plants that had a high pod weight per plant tended to produce $\mathrm{M}_{3}$-generation offspring that also had a high pod weight per plant, much higher than that of the mutagenic parent, Luhua $11 . \mathrm{M}_{4}^{-}$
\end{abstract}


generation seeds varied greatly in quality, and 35 individuals with an increased fat content $(>55 \%)$ were obtained. Overall, the results indicate that the combination of mutagenesis via mixed high-energy particle field exposure and tissue culture is promising for peanut breeding.

Key words: Peanut; Mixed high-energy particle field; Radiation; In vitro culture; Mutants

\section{INTRODUCTION}

As an important approach in crop breeding, mutagenesis can generate new genetic resources and accelerate strain improvement (Wu et al., 2002; Liu and Zheng, 2004). Radiation breeding uses physical mutagens to induce variations and then new varieties are directly or indirectly bred by selecting or identifying among the mutants (Maluszynski et al., 1995). Radiation breeding can induce DNA mutations (Xiang et al., 2002; Sun et al., 2006) or lead to chromosome variation (Wu et al., 2011). The combined application of radiation breeding and cross-breeding has led to the development of many improved varieties. With the development of biotechnology, in vitro mutagenesis is gaining increased attention (Liu and Zheng, 2002; Wu et al., 2005). The combined use of mutagenesis and plant tissue culture can increase the acquisition of mutants and selection probability. At the same time, because there is no seasonal limitation on mutagenic material, the combined use of mutagenesis and plant tissue culture can shorten the breeding cycle (Liu and Zheng, 2002; Wu et al., 2005).

In the tissue culture of explants, somatic embryogenesis is generally considered to originate from a single cell. Like somatic embryogenesis, mutation is also a unicellular event. Through the combined use of mutagenesis and plant tissue culture (especially plant regeneration via embryogenesis), chimerism of mutants can be avoided (Hong et al., 2003). Therefore, the combined application of mutagenesis and tissue culture is recognized as a valuable approach in crop breeding (Gao, 1992; Patade and Suprasanna, 2009).

Peanut is an important oil and industrial crop, and developing new peanut varieties with high yield and quality is an important goal of peanut breeding. However, the genetic basis of cultivated peanut varieties significantly limits the cross-breeding of peanut (Wang et al., 2013). Mixed high-energy particle fields are a mixture of various particles generated from the ground-based simulation of cosmic radiation. The use of mixed high-energy particle fields as physical mutagens is attractive because such fields are easy to produce and control and generate large biological effects (Liu et al., 2005; Guo et al., 2008).

In this study, we exposed seeds of the peanut cultivar Luhua 11 to a mixed high-energy particle field, then extracted, and cultivated their embryonic leaflets. In addition to studying the effect of different radiation doses on somatic embryogenesis and plant regeneration, we studied the trait variations of the offspring of the regenerated plants. Our goal was to develop a new approach for peanut breeding.

\section{MATERIAL AND METHODS}

\section{Peanut variety and mixed high-energy particle field radiation}

Mature seeds of Luhua 11, which is the major cultivated variety of peanut (Arachis 
hypogaea) in northern China, were obtained from an experimental field at Qingdao Agricultural University, Qingdao, China. Dry, plump seeds were selected and then irradiated in a mixed high-energy particle field at the Institute of High Energy Physics, Chinese Academy of Sciences (CAS). The radiation doses were 0, 67, 105, 150, and 196 Gray (Gy).

\section{In vitro culture of embryonic leaflets and plant regeneration}

After radiation treatment, the cotyledons of seeds were resected. The remaining embryos were then surface sterilized and placed in sterile water for 12 to $16 \mathrm{~h}$. Luhua 11 seeds with a radiation dose of 0 Gy were used as the control. Soaked embryos were placed in sterile culture dishes for embryonic leaflet separation. The separated embryonic leaflets were cultured on somatic embryo induction medium, which contained MS salts, $\mathrm{B}_{5}$ vitamins, $3 \%$ sucrose, $0.8 \%$ agar, and $10 \mathrm{mg} / \mathrm{L}$ 2,4-dichlorophenoxyacetic (2,4-D). Each treatment (radiation dose) was represented by approximately 90 explants. The culture conditions were as follows: $25 \pm$ $1^{\circ} \mathrm{C}, 13 \mathrm{~h} /$ day illumination, and 3000 lux illumination intensity.

After 4 weeks of culture in the induction medium, explant survival rate and somatic embryo induction rate were calculated according to the following equations:

Explant survival rate $(\%)=$ number of surviving explants/number of explants x $100 \%$ (Equation 1)

Somatic embryo induction rate $(\%)=$ number of explants forming somatic embryos/ number of explants x $100 \%$

(Equation 2)

Those explants that had formed somatic embryos were transferred to somatic embryo germination and regeneration medium, which contained MS salts, $\mathrm{B}_{5}$ vitamins, 3\% sucrose, $0.8 \%$ agar, and $4 \mathrm{mg} / \mathrm{L}$ 6-benzyl aminopurine (6-BAP). Tissue culture conditions were as described in the previous paragraph. After 8 weeks, the percentage of plants that had regenerated from the somatic embryos was determined according to the following equation:

Plant regeneration rate $(\%)=$ number of explants regenerating plantlets/number of original explants x $100 \%$

(Equation 3)

\section{Grafting, transplanting, and field management of regenerated plants}

In 2011, the regenerated plants of Luhua 11 were used as scions and were grafted onto stock plants (one graft per stock plant), which were 12-day-old plants of the peanut cultivar Huayu 23. The grafting was performed under sterile conditions as described by Zhao et al. (2013). The grafted plants were placed in fresh MS culture medium. After 2 to 3 days, the grafted plants were transplanted to pots and kept in an acclimation room at $22^{\circ} \pm 1{ }^{\circ} \mathrm{C}, 13 \mathrm{~h} /$ day illumination, and $2000 \mathrm{~lx}$ illumination intensity. After three weeks, the grafted plants were moved outdoors where they were exposed to normal sunlight and watered as required. After 3 to 5 days, the plants were transplanted in the field under shade cloth, where they were watered as required. The field was located at Qingdao Agricultural University and the soil had an aquic 
regime with a pH of 6.8. After 2 to 3 weeks, the shade cloth was removed, and the plants were managed in the same way as regular field plants. When each plant matured, its pods were harvested and stored separately from those of other plants.

\section{Field observations of $\mathrm{M}_{2}$-generation offspring of regenerated plants}

In 2012, we sowed the seeds harvested in 2011 so that the identity of each seed with respect to its source plant was maintained. The field, which was the same field used in 2011, was ridged and covered by plastic film, with $90 \mathrm{~cm}$ between adjacent ridges. Each ridge was planted with two rows of seeds, with one seed per planting hole and $17 \mathrm{~cm}$ between adjacent seeds in the row. At the same time, seeds of the mutagenic parent, Luhua 11, were planted as the control group. The $\mathrm{M}_{2}$-generation offspring plants were evaluated for variation rate in seedling vigor, plant height, branch number, pod number, pod shape, and other traits during the growing stages and at harvest. The trait variation rate was calculated as follows:

Trait variation rate $(\%)=$ number of plants with variation trait/number of total

$\mathrm{M}_{2}$-generation plants observed x $100 \%$

(Equation 4)

When the trait variation rate of the $\mathrm{M}_{2}$-generation plants was less than $85 \%$ of the lower limit value or greater than $115 \%$ of the upper limit value of the mutagenic parent, Luhua 11 (except for pod shape), we suspected that mutation had occurred in these plants.

The seeds were harvested separately for each plant in 2012 and were planted in 2013 following the same methods used in 2012. The plants growing in the field in 2013 were the $\mathrm{M}_{3}$-generation.

\section{Measurement of the quality characteristics of $M_{4}$ - and $M_{5}$-generation seeds}

A Matrix-E FTIR Spectrometer (Bruker Optics, Germany) was used to analyze the seeds of the $\mathrm{M}_{3}$-generation plants $\left(\mathrm{M}_{4}\right.$-generation seeds) for their fat, protein, oleic acid, linoleic acid, and palmitic acid content. For each plant line, one plant was tested twice. The average value of these two tests was taken as the effective value. The EXCEL and the SPSS software programs were used for statistical analyses. The seeds of $21 \mathrm{M}_{4}$-generation individuals with higher fat content $(>55 \%)$ and Luhua 11 seeds were further tested for their quality characteristics. Each plant line included two replications with 5 plants per replicate.

\section{RESULTS}

\section{Somatic embryo induction and plant regeneration}

After irradiation, the embryonic leaflets of Luhua 11 were cultured on somatic embryo induction medium. After 3 to 5 days, the incision of the embryonic leaflets began to swell and change from milk white to bright yellow. After 4 weeks on the induction medium, most explants that had been exposed to 0 or 67 Gy radiation had formed yellow-green somatic embryos or somatic embryo clusters, while a small number formed milk white calli. As the radiation level increased to $105 \mathrm{~Gy}$, the number of brown explants increased. Although some explants in the 105 Gy group were able to form a callus, the callus gradually turned brown, and 
some explants even directly formed somatic embryos as time elapsed (Figure 1a). Although the survival rate of explants decreased as the radiation treatment increased, survival was high (approximately 90\%) in the group exposed to 67 Gy radiation (Figure 2). The rate of somatic embryo induction was approximately $75 \%$ for the groups derived from seeds exposed to 0 and $67 \mathrm{~Gy}$; this rate also declined as the radiation treatment increased (Figure 2).

The explants that had formed somatic embryos were then transferred to the germination and regeneration medium. After 2 weeks, some somatic embryo clusters developed, and some somatic embryos grew into seedlings (Figure 1b). The regeneration rate was calculated after the explants had been cultured on the medium with $4 \mathrm{mg} / \mathrm{L}$ 6-BAP for 8 weeks. The regeneration rate declined as the radiation dose increased but was approximately $60 \%$ with 67 Gy (Figure 2).

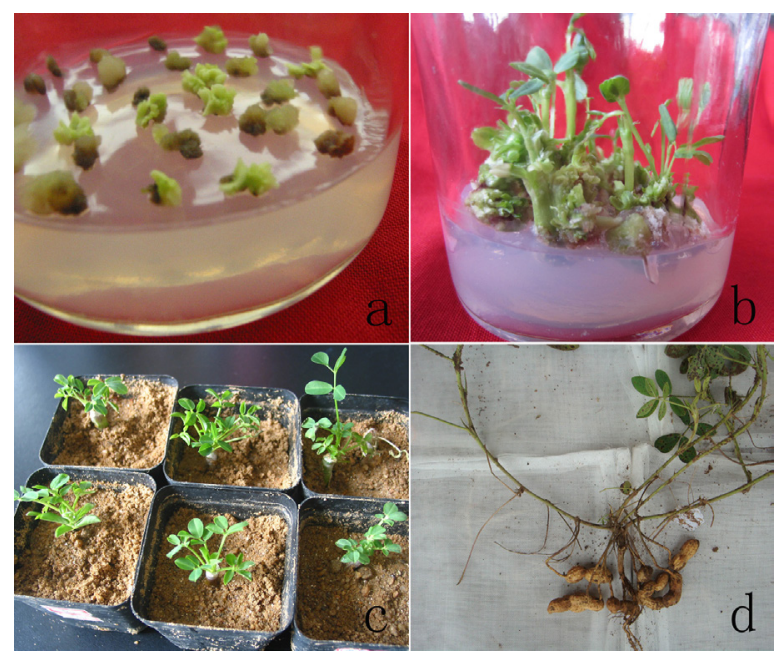

Figure 1. Development of peanut plants from seeds irradiated with a mixed high-energy particle field. a. Somatic embryos and calli that formed from embryonic leaflets obtained from seeds exposed to $105 \mathrm{~Gy}$. The leaflets were cultured on induction medium supplemented with $10 \mathrm{mg} / \mathrm{L} \mathrm{2,4-D.} \mathrm{b.} \mathrm{Plantlets} \mathrm{that} \mathrm{germinated} \mathrm{from} \mathrm{somatic}$ embryos on culture medium supplemented with $4 \mathrm{mg} / \mathrm{L}$ BAP. c. Regenerated plantlets obtained by grafting scions derived from irradiated tissue onto a rootstock. These $\mathrm{M}_{1}$-generation plantlets were transplanted in the field. d. An $\mathrm{M}_{1}$-generation plant that produced pods (the $\mathrm{M}_{2}$-generation) in the field.

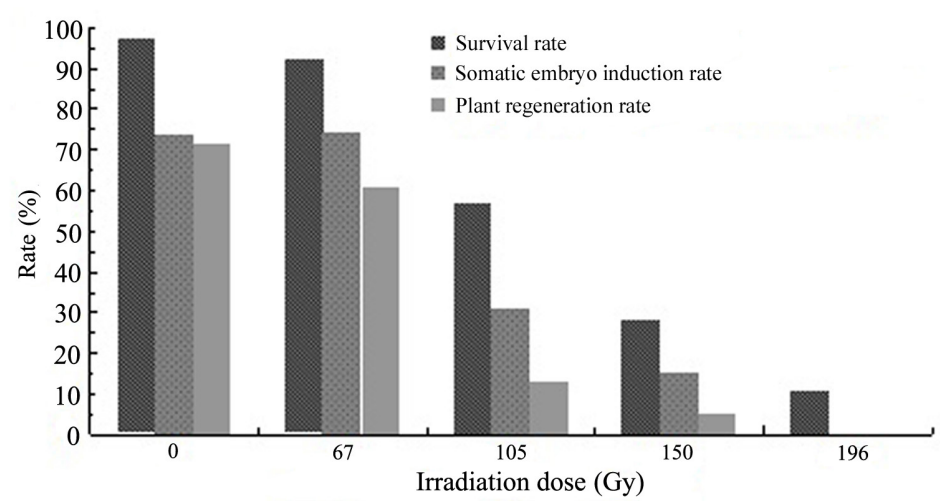

Figure 2. Influence of radiation from a mixed high-energy particle field on explant survival rate, somatic embryo induction rate, and plant regeneration rate in peanut plants. 
When the height of the regenerated seedlings exceeded $1.5 \mathrm{~cm}$, the plants were dissected from their base and aseptically grafted as scions. After acclimation (Figure 1c), these plants were then transplanted in the field as the $\mathrm{M}_{1}$-generation. Plants in the $67 \mathrm{~Gy}$ group and the 105 Gy group produced seeds (Figure 1d), but those in the 150 Gy radiation group grew poorly in the field and failed to produce seeds.

\section{Segregation and variation of $M_{2}$-generation plants}

In 2012, the seeds harvested from regenerated plants of 2011 were sown in the field at Qingdao Agricultural University; seeds of the mutagenic parent, Luhua 11, were sown as a reference. Some of the $\mathrm{M}_{2}$-generation plants that developed differed from their mutagenic $\mathrm{M}_{1}$-generation parents, as described in the following paragraphs.

During the seedling stage, some $\mathrm{M}_{2}$-generation plants showed low vigor and slow growth, and some were morphologically abnormal and late blooming (Figure 3a and b). In contrast, the mutagenic parent, Luhua 11, produced offspring that were uniform in growth and appearance (Figure 3c). Observations at harvest indicated that plant height and branch number were abnormal for some $\mathrm{M}_{2}$ plants. For example, the $\mathrm{M}_{2}$ offspring of plant no. 64, which was in the 67 Gy group, showed variation and segregation in branch number (Figure 3d); the $\mathrm{M}_{2}$ generation offspring of plant no. 4, which was in the 105 Gy group, showed variation and segregation in plant height; one plant was much shorter than its sister plants and the mutagenic parent (Figure 3e).

At more advanced growth stages and at harvest, variation and segregation were also evident in pod shape and pod size. The mutagenic parent, Luhua 11, produced pods with normal shapes, while the offspring of regenerated plants produced pods with abnormal shapes (Figure $3 \mathrm{f}$ and $\mathrm{g}$ ).

We determined the range in agricultural trait values and the trait variation rate for $289 \mathrm{M}_{2}$-generation individuals from the $67 \mathrm{~Gy}$ group (generated by $13 \mathrm{M}_{1}$-generation plants) and $136 \mathrm{M}_{2}$-generation individuals from the $105 \mathrm{~Gy}$ group (generated by six $\mathrm{M}_{1}$-generation plants). As noted in the methods section, the trait variation rate indicates the percentage of $\mathrm{M}_{2}$-generation plants that differ from the mutagenic parent for the indicated rate. In addition to variation in pod shape, variation was evident in stem height, lateral branch length, branch number per plant, total pod weight per plant, and weight per 100 pods. The trait variation frequency was much higher for the $105 \mathrm{~Gy}$ group than for the $67 \mathrm{~Gy}$ group. The trait variation rate for pod size was greater for these two groups than for the other radiation groups (Table 1).

\section{Pod production by $\mathrm{M}_{3}$-generation plants}

The seeds harvested from $\mathrm{M}_{2}$-generation plants in 2012 were individually sown in the experimental field in 2013. Evaluation of the offspring (the $\mathrm{M}_{3}$-generation) of those plants in the $\mathrm{M}_{2}$-generation whose pod production per plant exceeded $60 \mathrm{~g}$ revealed that although segregation continued in the $\mathrm{M}_{3}$-generation, the offspring $\left(\mathrm{M}_{3}\right.$-generation) of most $\mathrm{M}_{2}$-generation plants with large pod weight produced correspondingly heavy pods (Table 2). In the $67 \mathrm{~Gy}$ group, $38 \mathrm{M}_{3}$-generation individuals (generated from nine $\mathrm{M}_{2}$-generation individuals) produced $>50 \mathrm{~g}$ of pods, and 10 produced $>60 \mathrm{~g}$ of pods. In the $105 \mathrm{~Gy}$ group, six $\mathrm{M}_{3}$-generation individuals (from two $\mathrm{M}_{2}$-generation individuals) produced $>50 \mathrm{~g}$ of pods, and one produced $>60 \mathrm{~g}$ of pods. 

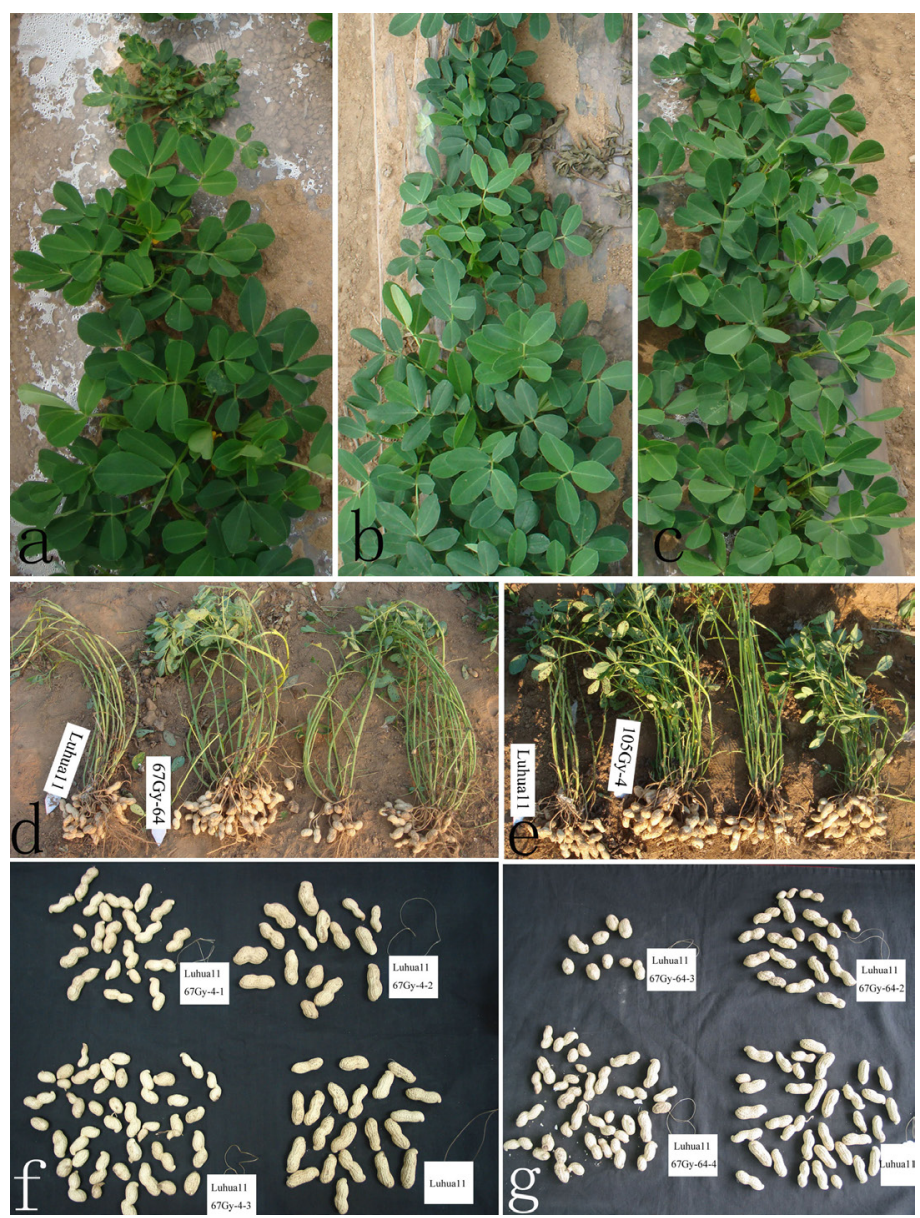

Figure 3. Variation and segregation of $\mathrm{M}_{2}$-generation peanut plants in terms of plant height, branch number, and pod shape following radiation from a mixed high-energy particle field. a. Among the offspring of plant no. 68 (in the 67 Gy group), one $M_{2}$ plant displayed morphological abnormalities at the seedling stage. b. Segregation was observed in the size of offspring of plant no. 7 (in the $67 \mathrm{~Gy}$ group). c. The mutagenic parent, Luhua 11, produced offspring that were uniform in growth and appearance. d. Abnormality and segregation were observed in branch number of the offspring of plant no. 64 (in the $67 \mathrm{~Gy}$ group). e. The offspring of plant no. 4 (in the 105 Gy group) displayed variation and segregation; one plant was clearly shorter than the others; $\mathbf{f}$. and g. Variation and segregation were observed in the pod size of the offspring of plant no. 4 and plant no. 64 (in the 67 Gy group).

We now consider some specific examples that suggest that phenotypic changes in pod production and other traits resulting from irradiation were inherited and that segregation continued into the third generation. In 2012, the pod weight per plant of offspring of plant no. 3 (3-6) in the 67 Gy group was $71.1 \mathrm{~g}$; in 2013 , among the $50 \mathrm{M}_{3}$-generation individuals, nine plants produced $>50 \mathrm{~g}$ of pods per plant, and one plant produced $76.4 \mathrm{~g}$ of pods. In another example, the $\mathrm{M}_{3}$-generation offspring of plant no. 65 (65-1) in the 67 Gy group included one plant that produced very few pods and three sister plants that produced $>50 \mathrm{~g}$ of pods per plant (Figure 4a). The offspring of plant no. 67 (67-1), which was also in the 67 Gy group, showed 
obvious segregation in plant height, branch number, and pod production per plant (Figure 4b). Among these offspring, one plant was much shorter than the others, two plants had increased branching (Figure $4 \mathrm{~b}$ ), and four plants produced $>50 \mathrm{~g}$ of pods per plant and up to $69.2 \mathrm{~g}$ of pods per plant. In contrast, the average pod weight per plant of the mutagenic parent, Luhua 11 , was only $37.9 \mathrm{~g}$, and the range was 35.1 to $42.6 \mathrm{~g}$.

Table 1. Variations in the main agricultural traits of $\mathrm{M}_{2}$-generation peanut plants (relative to Luhua 11, the mutagenic parent). Values indicate the range in trait values and the trait variation rate, which is the percentage of $\mathrm{M}_{2}$-generation plants that differed from the mutagenic parent in terms of the indicated trait.

\begin{tabular}{llcccccc}
\hline Radiation dose & $\begin{array}{l}\text { Trait range and } \\
\text { variation rate }(\%)\end{array}$ & $\begin{array}{c}\text { Stem height } \\
(\mathrm{cm})\end{array}$ & $\begin{array}{c}\text { Lateral branch } \\
\text { length }(\mathrm{cm})\end{array}$ & $\begin{array}{c}\text { Branch number } \\
\text { per plant }\end{array}$ & $\begin{array}{c}\text { Pod weight } \\
\text { per plant }(\mathrm{g})\end{array}$ & $\begin{array}{c}\text { Weight per } \\
100 \text { pods }(\mathrm{g})\end{array}$ & Pod shape \\
\hline $67 \mathrm{~Gy}$ & Range & $33-79$ & $29-72$ & $7-26$ & $7.8-71.1$ & $176-290$ & $\begin{array}{l}\text { Calabash, cocoon, } \\
\text { wasp waist, axe }\end{array}$ \\
& Variation rate & 4.5 & 2.8 & 1.7 & 6.2 & 1.4 & 6.9 \\
$105 \mathrm{~Gy}$ & Range & $28-56$ & $29-60$ & $5-22$ & $10.0-60.5$ & $179-288$ & Calabash, cocoon, axe \\
& Variation rate & 9.6 & 6.6 & 3.7 & 8.1 & 8.8 & 10.3 \\
Luhua 11 (0 Gy) & Range & $46-58$ & $45-62$ & $10-13$ & $38.4-47.4$ & $226-241$ & Ordinary shape \\
\hline
\end{tabular}

Table 2. Number of $\mathrm{M}_{3}$-generation peanut plants that produced $\geq 50.0 \mathrm{~g}$ of total pod weight per plant.

\begin{tabular}{|c|c|c|c|c|}
\hline \multirow[t]{2}{*}{ Radiation dose (Gy) } & \multirow[t]{2}{*}{$\begin{array}{l}\text { Identity of } \mathrm{M}_{2} \text {-generation offspring } \\
\text { of the original, regenerated plants }\end{array}$} & \multicolumn{3}{|c|}{$\begin{array}{c}\text { No. of } \mathrm{M}_{3} \text {-generation individuals that produced } \\
\text { the indicated pod weight per plant }\end{array}$} \\
\hline & & $50.0-54.9 \mathrm{~g}$ & $55.0-59.9 \mathrm{~g}$ & $\geq 60.0 \mathrm{~g}$ \\
\hline \multirow[t]{9}{*}{67} & $1-4$ & 1 & 1 & \\
\hline & $3-1$ & 3 & 1 & 1 \\
\hline & $3-2$ & & 2 & 1 \\
\hline & $3-6$ & 3 & 3 & 3 \\
\hline & $3-7$ & 2 & 1 & 2 \\
\hline & $23-3$ & 2 & & \\
\hline & $64-1$ & 3 & 1 & \\
\hline & $65-1$ & 1 & 1 & 1 \\
\hline & $67-1$ & 3 & & 1 \\
\hline \multirow[t]{2}{*}{105} & $5-3$ & 2 & 1 & 1 \\
\hline & $31-2$ & 1 & 1 & \\
\hline
\end{tabular}

For Luhua 11, the average total pot weight per plant was $37.9 \mathrm{~g}$ and the range was $35.1-42.6 \mathrm{~g}$.

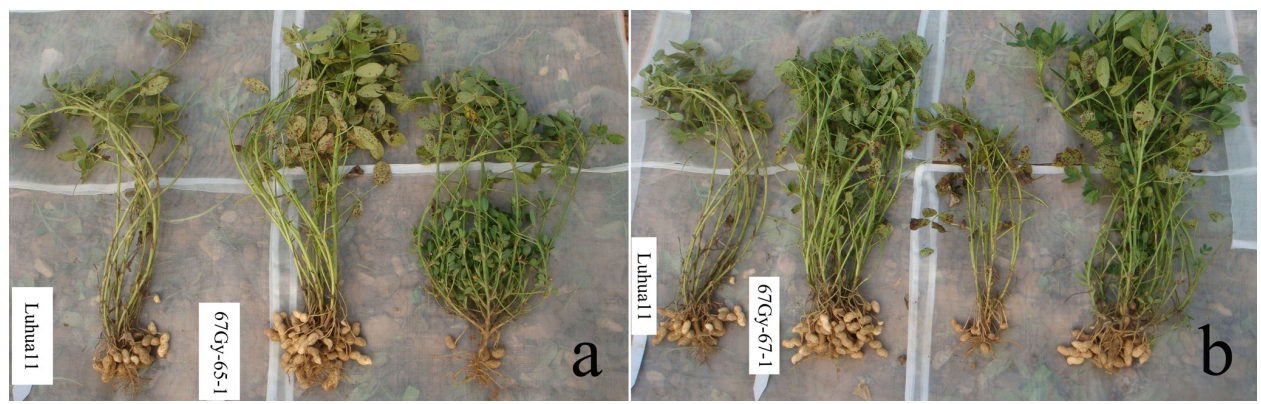

Figure 4. Variation among $M_{3}$-generation peanut plants in terms of plant height, branch number, and pod number following radiation from a mixed high-energy particle field. a. Among the offspring of plant No. 65 (65-1) (in the 67 Gy group), one plant (on the right) produced only a few pods while another (in the middle) produced more pods than the mutagenic parent (on the left). b. Among the offspring of plant No. 67 (67-1) (in the 67 Gy group), one plant (on the far right) produced more branches, one plant (second from the right) was shorter, and another (second from the left) produced more pods than the mutagenic parent (on the left). 


\section{Variation in the quality of $M_{4}-$ and $M_{5}$-generation seeds}

We evaluated the protein, oleic acid, linoleic acid, palmitic acid, and fat content of the $\mathrm{M}_{4}$-generation seeds produced by $150 \mathrm{M}_{3}$-generation plants (78 plants from the 67 Gy group and 52 plants from the 105 Gy group). The results are shown in Table 3. Irradiation with 67 Gy and 105 Gy had similar effects on the quality of seeds.

\begin{tabular}{|c|c|c|c|}
\hline \multirow[t]{2}{*}{ Quality characteristics } & \multirow[t]{2}{*}{ Mean value for Luhua 11} & \multicolumn{2}{|c|}{ Range for the $\mathrm{M}_{4}$-generation } \\
\hline & & 67 Gy group & 105 Gy group \\
\hline Protein content (\%) & 28.21 & $24.98-29.27$ & $25.00-28.30$ \\
\hline Fat content $(\%)$ & 52.78 & $47.50-58.53$ & $50.89-57.36$ \\
\hline Oleic acid (\%) & 54.84 & $41.39-58.77$ & $42.27-63.10$ \\
\hline Linoleic acid content (\%) & 27.57 & $24.06-29.91$ & 20.05-38.19 \\
\hline $\mathrm{O} / \mathrm{L}$ & 2.01 & $1.07-2.44$ & $1.11-3.21$ \\
\hline Palmitic acid content (\%) & 7.93 & $7.27-10.47$ & $7.88-10.52$ \\
\hline
\end{tabular}

Among the seeds of the $\mathrm{M}_{4}$-generation, 35 individuals had a fat content $>55 \%$, four individuals had an oleic acid content $>60 \%$, two individuals had a linoleic acid content $<22 \%$, and one individual had an oleic acid/linoleic acid ratio $>3$ (Figures 5 and 6).

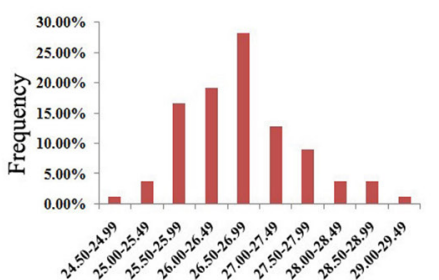

Protein content $(\%)$

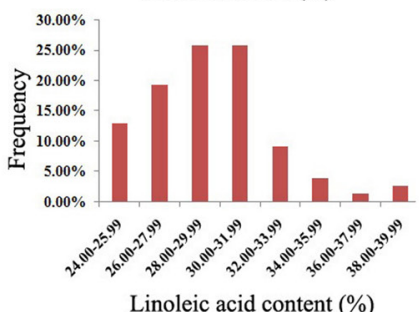

Linoleic acid content $(\%)$

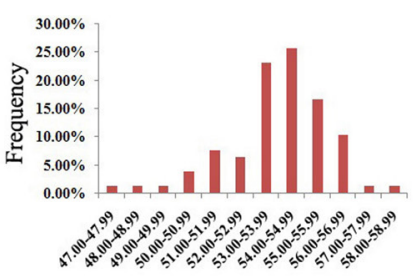

Oil content $(\%)$

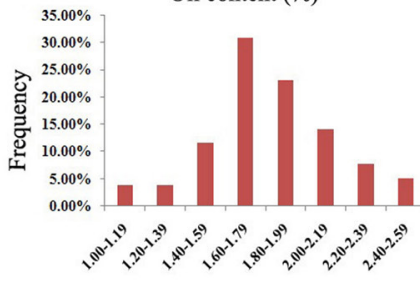

$\mathrm{O} / \mathrm{L}$

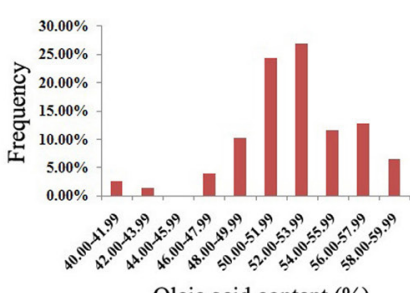

Oleic acid content $(\%)$

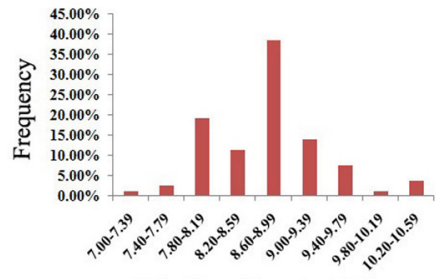

Palmitic acid content (\%)

Figure 5. Frequency distribution of quality characteristics of $\mathrm{M}_{4}$-generation peanut seeds in the 67 Gy radiation group. $\mathrm{O} / \mathrm{L}$ stands for the ratio of oleic acid/linoleic acid.

To further examine the changes in seed quality, we assessed the quality characteristics of seeds produced by $21 \mathrm{M}_{4}$-generation individuals with higher fat content (>55\%) and Luhua 11 seeds. The results showed that the fat content was substantially higher in seeds from 19 $\mathrm{M}_{4}$-generation individuals than in the seeds from the mutagenic parent, Luhua 11 (Table 4). 

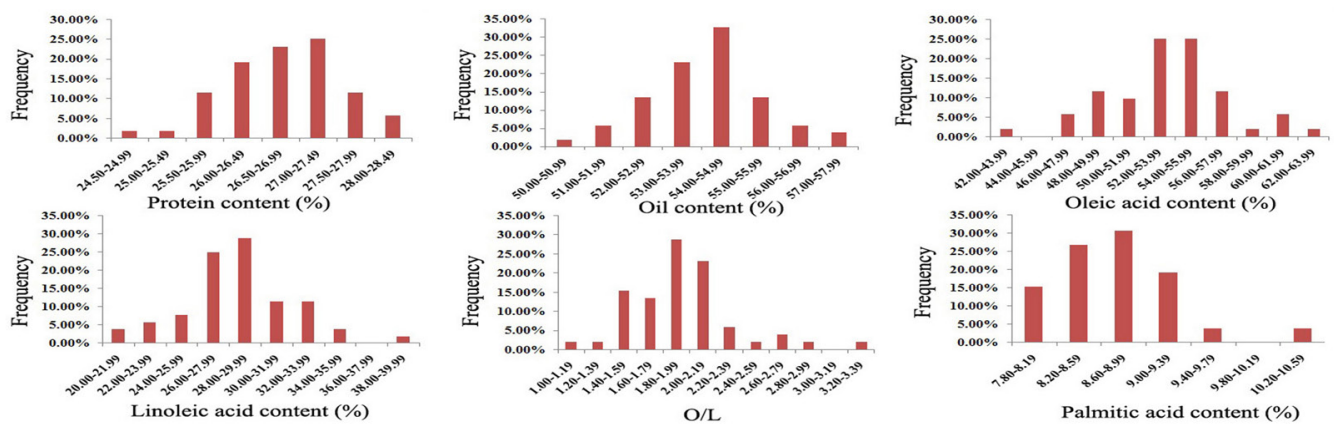

Figure 6. Frequency distribution of quality characteristics of $\mathrm{M}_{4}$-generation peanut seeds in the 105 Gy radiation group. $\mathrm{O} / \mathrm{L}$ stands for the ratio of oleic acid/linoleic acid.

\begin{tabular}{|c|c|c|c|c|}
\hline Radiation dose (Gy) & $\begin{array}{l}\text { Identity of } \mathrm{M}_{4} \text {-generation offspring } \\
\text { of the original, regenerated plants }\end{array}$ & Fat content $(\%)$ & Protein content $(\%)$ & Palmitic acid content (\%) \\
\hline 0 & Luhua 11 & $52.51 \pm 0.59$ & $27.19 \pm 0.43$ & $10.98 \pm 0.35$ \\
\hline \multirow{14}{*}{67} & $1-3-1$ & $58.12 \pm 0.42 * *$ & $24.38 \pm 0.44^{* *}$ & $6.89 \pm 0.10^{* *}$ \\
\hline & $1-7-2$ & $56.31 \pm 0.85^{* *}$ & $25.67 \pm 0.23 *$ & $6.17 \pm 0.15^{* *}$ \\
\hline & $1-8-1$ & $56.40 \pm 0.10^{* *}$ & $29.27 \pm 0.19^{* *}$ & $7.41 \pm 0.13^{* *}$ \\
\hline & $4-3-1$ & $54.32 \pm 0.14^{* *}$ & $24.97 \pm 0.49^{* *}$ & $6.65 \pm 0.26^{* *}$ \\
\hline & $4-8-1$ & $55.40 \pm 0.16^{* *}$ & $26.29 \pm 0.68$ & $6.75 \pm 0.17 * *$ \\
\hline & $4-13-1$ & $53.16 \pm 0.95$ & $24.42 \pm 1.05^{* *}$ & $8.41 \pm 0.86^{* *}$ \\
\hline & $4-13-2$ & $55.09 \pm 0.61 * *$ & $25.96 \pm 0.18^{*}$ & $7.53 \pm 0.32 * *$ \\
\hline & $7-10-1$ & $55.69 \pm 0.42^{* *}$ & $25.89 \pm 0.69^{*}$ & $7.27 \pm 0.09 * *$ \\
\hline & $7-11-4$ & $56.48 \pm 0.21^{* *}$ & $26.80 \pm 0.32$ & $7.94 \pm 0.03 * *$ \\
\hline & $65-3-3$ & $55.11 \pm 1.00^{* *}$ & $26.66 \pm 0.76$ & $5.53 \pm 0.17 * *$ \\
\hline & $65-11-2$ & $56.63 \pm 0.48^{* *}$ & $25.61 \pm 1.06^{*}$ & $8.52 \pm 0.23 * *$ \\
\hline & $65-11-3$ & $57.77 \pm 0.58^{* *}$ & $25.37 \pm 0.14 * *$ & $8.25 \pm 0.20 * *$ \\
\hline & $65-11-4$ & $54.22 \pm 0.26$ & $28.02 \pm 0.36$ & $9.61 \pm 0.95$ \\
\hline & $68-3-2$ & $58.68 \pm 0.18^{* *}$ & $24.53 \pm 0.09 * *$ & $9.04 \pm 0.31$ \\
\hline \multirow[t]{7}{*}{105} & $4-1-1$ & $55.93 \pm 0.38^{* *}$ & $27.45 \pm 0.10$ & $9.49 \pm 0.16$ \\
\hline & $4-1-2$ & $58.02 \pm 0.37 * *$ & $24.54 \pm 0.16^{* *}$ & $8.99 \pm 0.48^{* *}$ \\
\hline & $4-2-1$ & $57.56 \pm 0.28 * *$ & $25.34 \pm 0.15^{* *}$ & $8.91 \pm 0.07 * *$ \\
\hline & $4-2-2$ & $58.22 \pm 0.07 * *$ & $24.68 \pm 0.45^{* *}$ & $10.16 \pm 1.09$ \\
\hline & $6-3-1$ & $55.85 \pm 0.17 * *$ & $27.52 \pm 0.70$ & $10.54 \pm 0.44$ \\
\hline & $8-1-2$ & $57.42 \pm 0.58^{* *}$ & $25.60 \pm 0.17 *$ & $9.83 \pm 0.28^{*}$ \\
\hline & $8-2-1$ & $57.62 \pm 0.84 * *$ & $25.33 \pm 0.21 * *$ & $10.15 \pm 0.64$ \\
\hline
\end{tabular}

$*, * *$ Significantly different at $\mathrm{P} \leq 0.01$ and $\mathrm{P} \leq 0.05$, respectively.

\section{DISCUSSION}

Radiation mutagenesis can be used to develop crop plants with high yields and other desirable characteristics. Frequently used radiation mutagens include $\gamma$-rays, X-rays, fast neutrons, and ion beam and cosmic radiation in satellites or aerostats in space. The major particles in the mixed field included $\gamma$-rays, neutrons, protons, $\pi$, positrons, and electrons (Liu et al., 2005). Mixed high-energy particle fields have been used as mutagens in studies of other crops. Guo et al. (2008) found that the mutagenic effects on winter wheat were greater following irradiation with a mixed high-energy particle field than with $\gamma$-rays, and for varieties with high radiation sensitivity, the mixed high-energy particle field was more likely to induce 
beneficial mutations. In another study, greater increases of alfalfa plant height, yield, and crude fiber content were obtained with a mixed high-energy particle field than with $\gamma$-rays (Shang et al., 2008). The optimal mixed high-energy particle field radiation dose for alfalfa was determined to be 145 Gy followed by 195 Gy (Shang et al., 2009). In the current study, we used a mixed high-energy particle field to simulate the radiation environment in space and to achieve mutagenesis of peanut.

In our experiment, Luhua 11 seeds were irradiated with a mixed high-energy particle field, and their embryonic leaflets were taken as explants. The explants were then cultured according to an embryogenesis and regeneration system (Zhao et al., 2012). As the radiation dose increased, the survival rate, somatic embryo induction rate, and plant regeneration rate dropped sharply. When the radiation dose exceeded $105 \mathrm{~Gy}$, few or no regenerated plants were obtained, and those that were obtained performed poorly when transplanted into soil. Better results were obtained with 105 Gy and especially with 67 Gy.

Some researchers have indicated that the ideal dose of the mutagen is that which results in a relative survival rate or relative regeneration rate of approximately $50 \%$ (Wang et al., 2005). That conclusion, however, is inconsistent with our results. Although the relative survival rate was much greater than $50 \%$ with 67 Gy in the current study, we obtained better results with 67 Gy than with 105 Gy in that the 67 group produced a greater proportion of offspring with high pod yield than the 105 Gy group. Similar results were obtained in our experiments with fast neutron irradiation and $\gamma$-ray irradiation of Luhua 11 seeds, where a radiation dose resulting in $80 \%$ survival generated a greater proportion of offspring with high pod yield and high seed quality than a radiation dose resulting in 50\% survival (unpublished results). Based on our results, we suggest that a mutagen dose resulting in $>50 \%$ survival facilitates the acquisition of high-quality mutants.

We evaluated the yield of the offspring of the $\mathrm{M}_{2}$-generation plants that produced a high yield per plant. We found that although segregation continued in the $\mathrm{M}_{3}$-generation, the offspring ( $\mathrm{M}_{3}$-generation) of most $\mathrm{M}_{2}$-generation plants with high yields also produced high yields per plant, much higher than that of the mutagenic parent, Luhua 11. This showed that the high-yield characteristic induced by irradiation could be inherited. Because of drought in 2013, the yields tended to be low. The average pod weight per parent plant was $42.2 \mathrm{~g}$ in 2012 but was only $37.9 \mathrm{~g}$ per offspring plant in 2013.

Peanuts with a fat content $>55 \%$ are generally considered high-oil varieties, and we obtained a number of mutants that produced high yields and seeds with high oil content. Selfing will be conducted on the offspring of these individual plants with the hope of breeding new peanut varieties with high yield and high seed quality.

In this study, embryonic leaflets of peanut were irradiated with a mixed high-energy particle field. Every peanut seed contains eight embryonic leaflets, and each embryonic leaflet can produce several regenerated plants in tissue culture. After they are grafted and transplanted in the field, each regenerated plant can produce many seeds. In contrast, in conventional mutagenesis breeding, only one plantlet is produced per seed such that the mutated groups are often too small for breeding. In addition to providing an increased number of regenerated plants per mutagenized seed, the combination of irradiation and tissue culture can also avoid chimerism of mutants that occurs with conventional mutagenesis in breeding. Results of this study provide further evidence that combining mutagenesis and tissue culture is an effective approach in plant breeding. 


\section{Conflicts of interest}

The authors declare no conflict of interest.

\section{ACKNOWLEDGMENTS}

We thank Prof. Bruce Jaffee for critical reading of the manuscript. Research supported by the National High Technology Research and Development Program ("863" Program) Project of China (\#2012AA101202), the Shandong Province Science and Technology Development Plan Project (\#2014GNC110002), the Shandong Province Germplasm Innovation and Utilization Project, and the National Natural Science Foundation of the China (\#31301356 and \#31471542) and the International Atomic Energy Agency Project (\#RAS/5/056).

\section{REFERENCES}

Gao MW (1992). Hezu 8, a new wheat variety developed with in vitro mutation technique. Nuclear Phys. Rev. 9: 45-46.

Guo HJ, Liu LX, Han WB, Zhao SR, et al. (2008). Mutagenic effects of mixed particle field irradiation on wheat. Sci. Agric. Sin. 41: 654-660.

Hong YH, Zhu ZH, Huang H, Zhao Y, et al. (2003). On tissue culture and irradiation variation of Chrysanthemum. J. Hunan Agric. Univ. 29: 457-461.

Liu JP and Zheng CM (2002). Application of in vitro selection and somaclonal variation in improvement of disease resistance. Hereditas 24: 617-630.

Liu JP and Zheng CM (2004). Application in plant breeding by mutagenesis combined with plant tissue culture. Acta Agric. Shanghai 20: 19-22.

Liu LX, Guo HJ, Zhao LS, Zhao S, et al. (2005). Cytological effects of mixed particle field irradiation in wheat. Acta Agric. Nucl. Sin. 19: 327-331.

Maluszynski M, Ahloowalia BS and Sigurbjornsson B (1995). Application of in vivo and in vitro mutation techniques for crop improvement. Euphytica 85: 303-315.

Patade VY and Suprasanna P (2009). An in vitro radiation induced mutagenesis-selection system for salinity tolerance in sugarcane. Sugar Tech. 11: 246-251.

Shang C, Zhang YX, Tang FG, Li JL, et al. (2008). A comparison of quality variation of ${ }^{60} \mathrm{CO} \gamma$-rays and mixed highenergy particle field irradiation in Medicago sativa var. longmu 803. J. Nucl. Agric. Sci. 22: 175-178.

Shang C, Han GQ, Chen JS, Liu JL, et al. (2009). Effects on cold tolerance of $\mathrm{M}_{2}$ of Longmu No. 803 alfalfa seed pretreated with a mixed high-energy particle field. Acta Pratac. sin. 18: 164-168.

Sun JL, Du XM, Sun QX, Zhou ZL, et al. (2006). Genetic diversity of the progeny of cotton (Gossypium hirsutum L.) irradiated by gamma ray with SSR markers. Sci. Agric. Sin. 39: 1967-1976.

Wang J, Liu GR and Yang XJ (2005). Callus mutation with EMS and drought-resistant mutants selection for wheat. Chin. Agric. Sci. Bull. 21: 190-193.

Wang JS, Zhao MX, Qiao LX, Sui JM, et al. (2013). Effects of fast neutron irradiation on plant regeneration in embryonic leaflet culture of peanut (Arachis hypogaea L.). Chin. J. Oil Crop Sci. 35: 148-152.

Wu LR, Li ZC, Qiu QS and Miao HR (2002). Application of mutation techniques in peanut breeding in China. J. Nucl. Agric. Sci. 16: 334-336.

Wu RJ, Huang JH, Wen SX, Cai ZJ, et al. (2011). Change of mitotic behavior and ultra structure of 'FUJU' (Citrus reticulata Blanco) stem-apex clones after space flight. J. Nucl. Agric. Sci. 25: 259-265.

Wu WG, Liu GR and Yang XJ (2005). Applications of the mutation in connection with in vitro culture for plant breeding. Chin. Agric. Sci. Bull. 21: 197-201.

Xiang TH, Yang JB, Yang QJ, Zhu QS, et al. (2002). Molecular biological effect of ${ }^{60} \mathrm{Co}$ gamma-ray irradiation on rice genome DNA. Prog. Biochem. Biophys. 29: 754-759.

Zhao MX, Qiao LX, Sui JM, Tan LL, et al. (2012). An efficient regeneration system for peanut: somatic embryogenesis from embryonic leaflets. J. Food. Agric. Envi. 10: 527-531.

Zhao XM, Sun HY, Ji RR, Hu XH, et al. (2013). In vitro mutagenesis and directed screening for salt-tolerant mutants in peanut. Euphytica 193: 89-99. 